\title{
Las redes sociales y la transformación de las instituciones
}

\author{
Carmen Sánchez Galiano | Servicios Documentales, Instituto Andaluz del Patrimonio Histórico
}

URL de la contribución <www.iaph.es/revistaph/index.php/revistaph/article/view/4819>

La irrupción de las redes sociales en el trabajo de comunicación de las instituciones ha sido y es un camino largo y en algunos casos lleno de muchas contradicciones. Se ha ido trabajando de una manera intuitiva y con mucho esfuerzo por parte de los profesionales que se dedican a ello. Profesionales que han puesto su buena voluntad y capacidad para lo desconocido, además de llevar a cabo una formación y reciclaje para el manejo de un tema novedoso. En la mayoría de los casos, las instituciones cuentan con una realidad que no resuelve la implicación en la rápida dinámica del crecimiento tecnológico y por lo tanto no cuentan con personal técnico cualificado para estas tareas. Por otro lado, tampoco se ha reconocido la importancia, el valor y el poder que tienen estas herramientas y el trabajo de estos profesionales.

En este sentido, las instituciones se han ido subiendo al carro como han podido, algunas de manera más activa, otras menos, incluso algunas han conseguido logros y avances importantes. Por otro lado, también se han dado pasos en falso, el tiempo ha demostrado que el uso eficaz de las redes sociales va ligado a una transformación más moderna de las instituciones. Si este cambio se produce en la institución, el trabajo en redes sociales resulta más productivo. Es decir, el trabajo en redes debe estar unido a las líneas estratégicas de la institución y a la imagen que ésta quiera proyectar. A través del contenido que trabajemos en las redes podemos ir marcando las estrategias y a través del estilo utilizado plasmaremos una imagen de la institución. Además, los contenidos y el estilo deben estar acordes con las expectativas del público al que nos dirigimos.

Necesitamos, para que el trabajo en redes sea efectivo, características de comunicación muy novedosas y que están en contraposición a las características de comunicación más tradicionales de las instituciones. Llegar

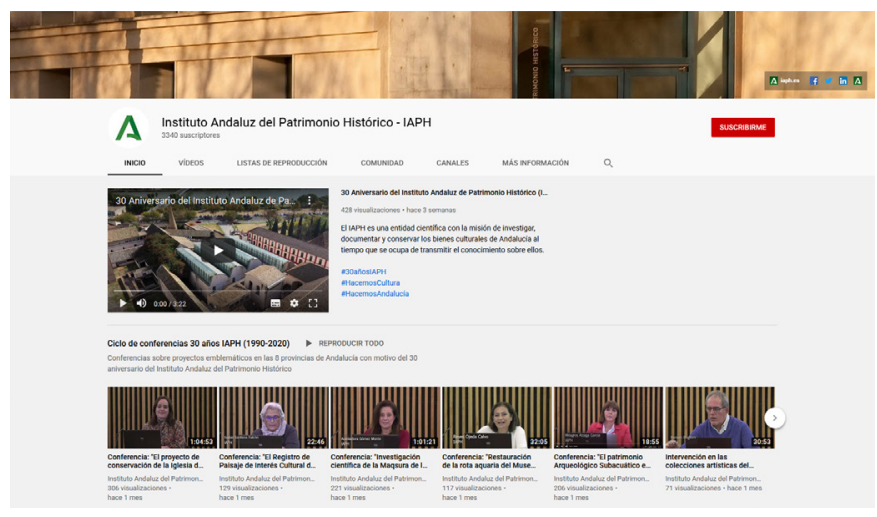

Canal YouTube del IAPH

a un punto intermedio entre lo tradicional y lo moderno es un desgaste de esfuerzos donde no se consiguen los objetivos para los que se han creado este tipo de herramientas.

Otro punto importante y a tener en cuenta, después de estos años de rodaje, es que las redes sociales son un negocio más, son herramientas útiles fundamentalmente como escaparate para la institución, pero podemos optar, o bien, por estar en redes como contenedores de información o podemos optar a desarrollar una estrategia de marketing y negocio para conseguir beneficios para nuestra institución.

Esta última opción sería un modelo mercantilizado, basado en el algoritmo que te imponen las propias redes en el mercado de la competencia. Es decir, si queremos destacar debemos realizar una inversión económica para que nuestro contenido lo vea el mayor número de personas posibles.

En este punto, existe un gran desconocimiento por parte de las instituciones, no se trata de publicar información únicamente y conseguir seguidores, se trata de traba- 
a debate Comunicación y redes sociales en instituciones culturales

| coordina Candela González Sánchez

jar en una estrategia tanto de contenidos como de estilo de comunicación pero además para llegar al público al que nos queremos dirigir, aquel al que le interesa nuestro producto, tenemos que pagar para que el contenido se muestre.

Las instituciones pueden decidir entrar o no en el juego del mercado, pero desde luego esa es la clave o la trampa de la situación actual en la que se encuentran las redes sociales. Implicarnos en este negocio o no es una decisión que debe ser madurada a nivel institucional, no se trata de decidir en qué redes sociales quiere estar presente la institución, es una decisión con un trasfondo mayor.

Por lo tanto, hay dos factores que influyen en el posicionamiento de la institución en redes: uno interno, que sería la falta de implicación de la institución de forma general y desde todos los ámbitos; y el externo que serían los criterios o condicionantes que nos imponen las propias redes sociales.

Es necesario tomar conciencia de lo que esto supone para una institución ya que es un trabajo laborioso y complicado. De hecho, las grandes empresas manejan estas estrategias desde un departamento específico formado por un equipo de profesionales competentes en estas materias. Las instituciones deberán buscar su modelo de trabajo, según su realidad, no se pretende copiar la estructura de trabajo de las grandes empresas pero sí pueden ser nuestro reflejo.

Consideramos primordial un equipo de profesionales trabajando en el análisis y seguimiento de las estrategias planteadas para ir probando y buscando la manera de conseguir explotar todo el potencial que las redes sociales nos ofrecen.

De todas formas, siempre podemos estar presentes en las redes como simples contenedores de información, de esta manera la institución responde a los nuevos tiempos y a las nuevas realidades existentes pero no consigue un uso eficaz y eficiente de las mismas.
Según lo comentado, entendemos que existe una diferencia entre el trabajo cultural en redes no institucionales y las institucionales. El trabajo en redes no institucionales cuenta con una mayor capacidad de adaptación, de innovación, funcionan a la perfección con estas herramientas y quizás es donde deberíamos reflejarnos. En cambio, el trabajo cultural en las instituciones se encuentra más delimitado, aún las instituciones culturales deben dar pasos grandes para entender la idiosincrasia y el valor e importancia que tienen los medios sociales actualmente.

No son herramientas contenedoras de información, las redes sociales son en realidad un entramado más profundo y complicado que nos permiten llevar a cabo unas estrategias de comunicación más revolucionarias. No obstante, las instituciones culturales están en un proceso de adaptación, de creación y búsqueda bastante interesante. Aunque para conseguir el efecto adecuado en las redes sociales la transformación debe ser de la institución para luego lograr el resultado que esperamos en estas herramientas.

Es importante que las instituciones pierdan el miedo en la comunicación con el exterior, una vez salvado esa diferencia entre la institución y la herramienta ya podremos hacer un uso eficaz y efectivo de las redes, mientras tanto las redes institucionales serán contenedores de información.

La institución debe posicionarse, generar ideas y opinión a partir de ahí el triunfo en las redes sociales está asegurado. 